page in question in the publication of Landa's text procured by D. Juan de Dios de la Rada y Delgado. In the hieroglyphic writing the element Fig. 16 occurs as a substitute for the element Fig. 17. The latter, probably, is intended to render the head and the wing of a bird.

It is quite probable that in Landa's time the Mayas used to write in the manner indicated by Landa; we observe the same in the Mexican area. At a certain time after the conquest the Indian writers were inclined to restrict the phonetic value of their old hieroglyphs, in order to write with them in the same manner as the Spaniards did with their respective hieroglyphs. Compare the so-called Codex Vergara of the Aubin-Goupil collection. But this was not so in ancient times. Certainly there existed in the Maya writing compound hieroglyphs giving the name of a deity, a person, or a locality, whose elements united on the phonetic principle. But as yet it is not proved that they wrote texts. And, without doubt, great part of the Maya hieroglyphs were conventional symbols, built up on the ideographic principle.

In order to illustrate the combination of his letter symbols, Professor Thomas gives a few interpretations of groups of compound characters.

This first group (see above, p. 45, Fig. 2) contains in the second hieroglyph (reproduced in my Fig. 24) the elements given by Landa (Fig. 25) as expressing the sounds $l$, e, i.e., $l e$, the lasso, the sling; and, indeed, in the figure below a turkey is seen hanging in the sling. I do not venture to settle the question by giving an explanation of this hieroglyph. I will only remark that the second element of this sign, that given by Landa as expressing the sound $e$, occurs in various compound hieroglyphs (see Figs. 26-28). In all these cases the action represented refers to handling a rope or to working up thread. Fig. 26 (taken from Codex Troano $31 * b)$ refers to bandling the rope trimmed with thorns that the penitent used to draw through the pierced tongue (see the Relief of Lorillard City, published by Charnay). Figs. 27, 28 (taken from Codex Troano, $11^{*}$ ) refer to weaving and embroidery. It would be a curious coincidence that the words expressing these different actions should all contain an $e$, while considering the idea expressed, the coincidence is a given one.

Considering the third hieroglyph of this group - which is indeed that of the turkey, cutz (see Fig. 19), one is in like manner induced at the first glance to think of a phonetic constitution. For the first element is that of the day cauac, given by Landa (Fig. 3) as expressing the sound $c u$. And the second elementwanting in Landa's as well as in Professor Thomas's list of letter glyphs - would seem to record the sound $t z$, because it renders the conventional design of a headless carcass or skeleton, tzictzac, seen from behind, or in front, with its ribs and the anal opening. Compare the Fig. 23, the design of a skeleton (the death-god) seen "in profile." Nevertheless, it would be a hasty conclusion to proclaim as established and beyond doubt the phonetic constitution of this hieroglyph. For the same element of the skeleton occurs in other hieroglyphs, expressing things the names of which do not contain a trace of the sound $t z$. Fig. 20 is the hieroglyph of the dog, pek; Fig. 21, that of the dog of the heaven that carries the lightning; Fig. 22 is the hieroglyph of the month kan-kin, "the yellow (or ripe) sun."

But it is principally the first hieroglyph of the group in question that rouses the gravest doubts about the rightness of Professor Thomas's interpretation. The whole group forms part of a series of representations, filling the upmost division of Plates $24 *-20 *$ of the Codex Troano, and recording, undoubtedly, the capturing of animals. The series begins with the prey-gods of the five regions. These are followed by various representations showing the hunting god - with a captured turkey under the arm, or holding a bag, or armed with spears and throwing-stick (Fig. 33); the black god (Fig. $31=$ Ekchuah ?), and different captured animals, an armadillo (?) in the trap loaded by heavy stones, a turkey seized by the snare, a deer seized by the snare, a deer impaled on the pointed flint erected in the bottom of the pit, a pizote seized by the snare, and a turkey entangled in the hunter's net. Each figure is accompanied by a group of four hieroglyphs (as a rule). The first hieroglyph is the same in all the groups (see Fig. 2, page 45, and my Figs, 31-33), and undoubtedly refers to the action of capturing.
This action is clearly indicated by the form of the hieroglyph that exhibits the head of the victim with the bloody, empty eye-hole, the conventional symbol of sacrifice. This head is held within a sling, the knot of which is seen on the summit. Compare the more accurate design of this hieroglyph in Fig. 18, taken from the Dresden Codex 60a. In this hieroglyph all is figurative and ideographic; no trace of phonetic constitution can be observed.

The fourth hieroglyph of the group (Fig. 29) is interpreted by Professor Thomas as the second day of the month yax-kin. But this is obviously erroneous. There does not exist a numeral designation with crosses between the dots. Fig. 29 seems a variant of the hieroglyph seen in Fig. 30 placed on a bowl. In the latter hieroglyph, the second element signifies $k a n$, the yellow color. It is replaced in Fig. 29 by the element kin, the sun. The hieroglyph Fig. 30 - which in a former communication was interpreted by Professor Thomas as signifying " moisture"- occurs on different pages of the Dresden Codex among the figured representations of offerings (turkey, lizard, fish, deer). Undoubtedly it means an eatable thing, perhaps honey.

I do not enter into a discussion of the second sample given by Professor Thomas (Fig. 3, p. 45), because I find nothing in it that might impel me to accept the translation given by him.

As to Professor Thomas's third sample (Fig. 4, p. 45), I agree with him that the boards covered with the hieroglyphic design of the day cauac may be intended for "wood" or "wooden." The same board is seen in Troano $12 * \mathrm{c}$, but fitted with a twisted handle on its surface. Here the first and fourth hieroglyph of the group are also seen; the second one is wanting. Variants of the first hieroglyph occur in Troano $35 \mathrm{a}, 35 \mathrm{~b}, 34 \mathrm{~b}$, and Cortes $21 \mathrm{a}$, where the figure below shows the god beating a drum. Professor Thomas's explanation, mul-cin, "collect together," is merely hypothetical. The same applies to the fourth hieroglyph. It is the same as that given by Landa as expressing the sound $x$. It is materially identical with that of a well-known deity exhibiting in his face the same characteristic design as the face that forms the essential part of this hieroglyph. In Troano $11 *$ this hieroglyph accompanies the elements which seem to express the action of weaving. And on the two contiguous plates, Codex Troano $35 *$ and Cortes 22 , it is connected with red numerals and forms a row alternating with rows of various offerings. It is scarcely probable that in all these cases the reading xaan should correspond to the matter expressed.

The problem of the Maya writing is a difficult one. I cannot convince myself that the list given by Professor Thomas as letter glyphs acts as a key to its interpretation. For the samples of translation he adduces are not forcible, and include misunderstandings. In my opinion, in the present state of things it would be far more appropriate to point out the real meaning, as to the matter expressed, of each hieroglyph. The determination of their phonetic value will then follow, and consequently will then be done with much more accuracy. DR. SkLER.

Steglitz, Germany, Aug. 7.

\section{The Fundamental Hypotheses of Abstract Dynamics.}

IN Professor MacGregor's interesting paper "On the Fundamental Hypotheses of Abstract Dynamics," the suggestion is made that a fourth law of motion should be added to the three laws of Newton. The proposed law is, in effect, that the magnitude of the stress between any two particles depends solely upon the distance between those particles. Combined with Newton's third law, the new law is thus stated :-

"Natural forces may be considered to be attractions or repulsions whose magnitudes vary solely with the distances of the particles between which they act."

The reason assigned for introducing this law is that " the fundamental hypotheses of dynamics should either include" the law of the conservation of energy "or give it by deduction." This reason seems hardly sufficient. In order that the law of the conservation of energy may be true it is not necessary that the stress between two particles shall depend solely upon the distance between them. It is necessary only that "the work done during any change of configuration of a system of particles acted upon 
by natural forces" shall depend "only upon the changes in the positions of the particles, and not upon the paths by which, or the velocities with which, they have moved from the old positions to the new."

Now let $F$ denote the magnitude of the stress between any two particles of a system and $r$ the distance between those particles; then $P d r$ is the work done by this stress during an infinitesimal displacement of the system. The work done by the stresses between all particles of the system during a finite displacement is $\Sigma \int P d r$, in which the summation is extended to all pairs of particles and the integration covers the whole displacement of the system. Now if $\Sigma P d r$ is the differential of a function of the quantities $r$, the value of the integral will depend only upon the initial and final relative positions of the particles. But the assumption that each $P$ is a function of the corresponding $r$ only (in accordance with the proposed fourth law) is only one of many possible assumptions, any one of which would make $\Sigma P d r$ the differential of a function of the quantities $r$. The mathematical statement of the condition that $\Sigma P d r$ shall be a perfect differential is given in treatises on "Differential Equations."

It thus appears that the principle of the conservation of energy does not require the truth of the proposed fourth law. The law may be true nevertheless; but it may well be questioned whether its truth is established with any such degree of probability as would entitle it to rank with the laws of Newton as a fundamental hypothesis of dynamics.

L. M. Hoskins.

Madison, Dis., Aug. 16.

\section{The Black-Knot.}

ON p. 10, Vol. XX., of Science appears an instructive chapter on "Black-knot," a fungous disease of the plum and cherry, of much trouble to cultivators. A point of additional scientific interest is that this fungus illustrates a principle long since presented by the writer of this, that nature does not place species where it is for the best interests of the individuals of the species, but generally has some ulterior purpose not always apparent to us who are eager to uncover her intentions. For instance, there are numberless trees and shrubs that struggle along in swamps, and are rarely found elsewhere, and these have come to be known as "swamp-lovers," but close observation has shown that the same tree or shrub will thrive immeasurably better when removed to dry ground.

On the writer's grounds is a specimen of Clethra ulnifolia, fifteen feet high and as much wide on an especially dry spot, and growing with a luxuriance rarely seen in the swampy spots where nature has located the plants. Some reason has been found for the appearance of these plants in swamps and not in dry ground naturally in the fact that the seeds will not sprout in dry, but only in wet ones. It looks like a fiat of nature. "Though you would like to grow in dry places you shall not. Something must grow for my purposes, in swamps, and you have to do it." They can only be found where the seed will sprout.

It has always seemed to the writer that it was one of the weaknesses of many discussions in the study of development, that it was generally from the individual standpoint. Nature cares only for the individual, therefore questions of nutrition, fertilization, and others are all viewed in their relation to the plant's "struggle for life." It seems rather that nature cares but little for the individual, and stands ever ready to sacrifice the whole stock when it interferes with some purpose, which we have seldom been able to fathom.

Coming to the black-knot on the plum and cherry, we have here a destructive American species Spharia (Plowrightia) morbosa, of little injury in its native state, thriving amazingly when it can get as a host-plant the European domestic plum or European morello cherry. It thrives in these cases with a vigor it never shows at home. I have seen it in many parts of the east on the wild dwarf choke-cherry, Cerasus Virginiana; in Colorado on its close ally Cerasus demissa; in North Carolina sparingly on Prunus chicasa; and in the White Mountains on the red cherry, Cerasus Pennsylvanica. Recently in driving through various localities on Mt. Desert Island, it was seen on the latter much more abundantly than in any of the former cases noted; but never anywhere with the amazing destructiveness it presents in these garden representatives of foreign species. In Pennsylvania, and probably other States, the cultivated cherry has been wild for over a hundred years. It is abundant, and in some cases so numerous as to be the chief element in a piece of woodland. But though it is evidently the foster-child of the cherry and not the plum, it prefers the plum and the sour cherry. The knot is rarely found on the wild cherry trees of the sweet cherry species. For all its long hereditary cherry taste, it rushes to the plum and the morello with as much avidity as if long-continued "environment" had induced the love.

It seems to be forgotten in many discussions of the black-knot that it is an American parasite, and that it may be found in quantities everywhere that the botanists look for it. When, therefore, the State of New York tries to "stamp it out" by leg. islating against garden trees affected with the fungus, it seems like bailing out the ocean with a bucket. Of course, cutting down and burning destroy many spores, but the wild nests send forth myriads of young to take the places of the domesticated foes destroyed.

Thomas MeEHan.

Germantown, Pa.

\section{Hectoring a Hawk.}

EARLY one morning in August, while concealed in the grass and bushes of a White Mountain meadow, I saw an interesting encounter between a sharp-shinned hawk and a number of blue-jays and pigeon woodpeckers. Four of the woodpeckers were quietly preaning themselves in a dead pine by the lake shore, when suddenly a small and beautifully proportioned hawk dashed into their midst. They scattered shrieking, and found shelter in a fringe of woods near by. Their cries brought a kingbird to the spot, and the hawk was promptly attacked by the pugnacious fly-catcher and compelled to follow the flickers into concealment. The kingbird, satisfied with routing the hawk, hovered away over the meadow out of sight, and not long after the hawk reappeared and perched in the dead tree.

From time to time one or more of the woodpeckers came back to the tree and were at once charged by the hawk. In each instance they showed superior speed and escaped by their rapid flight. Their noise attracted the attention of a flock of about twenty blue-jays, and presently the blue-winged pirates came sailing over the meadow by twos and threes. As they neared the dead pine the hawk darted downward after their leader. The jay plunged quickly into the bushes, uttering wild cries and squawks, which were re-echoed by his companions. The hawk returned to the pine squealing pettishly, and the jays closed in upon him. They scaled the lower branches of the dead tree; they capped the neighboring maple saplings and alders; they watched for chances to brush past the hawk on his perch, and they assailed him with all the invective of their ample vocabulary. They threw themselves into the sport, as they seemed to regard it, with all the energy of boys playing "short fox."

The hawk took the matter much more in earnest; for he was hungry, and striving for a breakfast. Again and again he shot from the lofty branches of the pine, aiming first at one jay, then at another. By and by all the flickers returned, and added to the confusion by their cries and rapid excursions around the tree. The hawk in several instances seemed to lack but a single wingbeat of success, but the hour drew on without his making a capture. He grew weary. His plumage showed the chafing of the bushes. He chose lower and lower branches for his rests, and finally his sallies seemed directed more towards clearing the tree of noisy birds than to the capture of any one of them. At last he abandoned the dead pine and perched in trees having foliage. The jays followed him jeering, and he shifted his ground slowly until he gained the woods and disappeared. Then the jays crowded into the lower branches of the pine, hopped up from limb to limb until one after another gained the summit, and proved to the whole meadow that they had won the battle and fairly worried the hawk away.

The drama seemed to me to be significant in two ways; first, as 